\title{
PULSED POWER ACCELERATORS AT CEM-UT
}

By:

\author{
R.J. Hayes \\ R.L. Fuller \\ J.P. Kajs \\ R.L. Laughlin \\ R.C. Zowarka
}

Digest of Technical Papers, 8th Pulsed Power Conference, San Diego, CA, June 16 to 19, 1991, pp. $50-53$

PN 181

Center for Electromechanics

The University of Texas at Austin

PRC, Mail Code R7000

Austin, TX 78712

(512) 471-4496 


\title{
PULSED POWER ACCELERATORS AT CEM-UT
}

\author{
R.J. Hayes, R.L. Fuller, J.P. Kajs, R.L. Laughlin, and R.C. Zowarka
}

Center for Electromechanics

University of Texas at Austin

BRC, Bldg. 133

Austin, TX 78712

\begin{abstract}
An overview of four accelerator programs utilizing pulsed power is presented. The goals of each project, a description of the power supplies and launchers utilized and test results from each program are provided. The four projects presented illustrate a variety of uses for electromagnetic (EM) launchers and the potential advantages and disadvantages of four different launcher systems. Included in the paper are micrometeorite impact studies of 50 to $500 \mu \mathrm{m}$ diameter glass beads accelerated up to $11 \mathrm{~km} / \mathrm{s}$ with plasma armatures and 2.5 $\mathrm{kg}$ solid armature packages launched at $2.6 \mathrm{~km} / \mathrm{s}$ (a record 8.1 MJ of muzzle energy). A compact rep-rateable augmented rail launcher and compulsator system weighing less than $1,100 \mathrm{~kg}$ is also described. Finally a skid mounted rep-rateable launcher system capable of providing $9 \mathrm{MJ}$ of muzzle energy is discussed.
\end{abstract}

\section{Introduction}

The Center for Electromechanics at the University of Texas (CEM-UT) was started in 1975 with the primary goal of studying the generation of and applications for pulsed power. Development of electromagnetic launchers or railguns began in 1979 after a visit to the railgun facility at the Australian National University [1]. The first accelerator and pulsed power systems built at CEM-UT utilized parallel copper rails and low energy capacitors. Now in addition to simple square bore parallel plate launchers, a wide variety of other launcher and power supply concepts are being tested (table 1). The uses for these are as wide in scope as the launcher systems themselves. Four of these systems and the experimental results gathered from their testing are presented. For information on induction launcher programs at CEM-UT please refer to a companion paper [2].

\section{Micrometeoroid Launchers}

Under contracts from Lockheed's Palo Alto Research Laboratory and Martin Marietta Corporation, CEM-UT has carried out 101 hypervelocity micrometeoroid impact simulations using EM launchers. The purpose of the program is to determine the effects of fine particles colliding with structures in space. Using $1 \mathrm{~m}$ long, squarebore launchers with molybdenum rails and either glass-filled polycarbonate or black-granite sidewalls, 50 to $550 \mu \mathrm{m}$ diameter glass beads were accelerated to velocities between 6 and $11 \mathrm{~km} / \mathrm{s}$ [3]. The beads were fired using plasma armatures at targets of aluminum, quartz, silicon, and other proprietary materials. The tests were designed to determine the feasibility of using EM launchers to accelerate particles with masses of $10^{-4}$ to $10^{-7} \mathrm{~g}$. These sizes of particles are less than that launched effectively by light gas guns and above the range of electrostatic accelerators.

Launching a nonconductive material such as glass requires the use of a separate armature. Thin strips of aluminum foil 0.254 to $0.0254 \mathrm{~mm}$ thick were bonded to an
Table 1. Some of the twenty launchers currently available or in fabrication at CEM-UT

\begin{tabular}{|c|c|c|c|c|}
\hline $\begin{array}{l}\text { Program and Power } \\
\text { Supply }\end{array}$ & $\begin{array}{l}\text { Launcher } \\
\text { Length } \times \text { Bore } \\
\text { Dimension }\end{array}$ & $\begin{array}{l}\text { Armature } \\
\text { Type and } \\
\text { Mass }\end{array}$ & $\begin{array}{l}\text { Package } \\
\text { Mass Total } \\
\text { (g) }\end{array}$ & $\begin{array}{l}\text { Velocity } \\
(\mathrm{m} / \mathrm{s})\end{array}$ \\
\hline $\begin{array}{l}\text { Micrometeoroid } \\
\text { Square Bore \& } 1 \mathrm{MJ} \\
\text { Capacitor Bank }\end{array}$ & $\begin{array}{l}1 \mathrm{~m} \times 12.7 \mathrm{~mm} \\
\text { Square Bore }\end{array}$ & $\begin{array}{c}\text { Al. } \\
\text { Plasma } \\
\text { NA }\end{array}$ & $\overline{N A}$ & $\begin{array}{l}6,000- \\
11,000\end{array}$ \\
\hline $\begin{array}{l}\text { GEDI Hypervelocity } \\
\text { Launcher \& } 10 \mathrm{MJ} \\
\text { HPG \& Capacitor } \\
\text { Bank }\end{array}$ & $\begin{array}{l}2 \mathrm{~m} \times 12.7 \mathrm{~mm} \\
\text { Square Bore }\end{array}$ & $\begin{array}{c}\text { Al. } \\
\text { Plasma } \\
0.06 \mathrm{~g}\end{array}$ & 2 & 6,200 \\
\hline $\begin{array}{l}\text { Small Caliber Rep" } \\
\text { ratable Gun \& } 9 \mathrm{MJ} \\
\text { Air Core } \\
\text { Compulsator }\end{array}$ & $\begin{array}{c}1.6 \mathrm{~m} \times 15 \mathrm{~mm} \\
\text { Round Bore }\end{array}$ & $\begin{array}{l}\text { Hybrid } \\
\text { Al. } \\
22 \mathrm{~g}\end{array}$ & 32 & 1,725 \\
\hline $\begin{array}{l}\text { Coaxial Induction } \\
\text { Accelerator \& } \\
\text { Actively Switched } \\
\text { Capacitors }\end{array}$ & $\begin{array}{c}\text { *10 } \mathrm{m} \times 45 \mathrm{~mm} \\
\text { Round Bore }\end{array}$ & $\begin{array}{l}\text { Multiturn } \\
\text { Coil } \\
225 \mathrm{~g}\end{array}$ & 225 & $* 2,000$ \\
\hline $\begin{array}{l}\text { 9 M] Single Shot Gun } \\
\text { (SSG) \& 60 MJ } \\
\text { Homopolar Power } \\
\text { Supply }\end{array}$ & $\begin{array}{l}10 \mathrm{~m} \times 90 \mathrm{~mm} \\
\text { Round Bore }\end{array}$ & $\begin{array}{l}\text { Hybrid } \\
\text { Al. } \\
1,100 \mathrm{~g}\end{array}$ & 2,440 & 2,600 \\
\hline $\begin{array}{l}\text { MI Field Based } \\
\text { Rep-ratable Gun \& } \\
200 \text { MICompulsator }\end{array}$ & $\begin{array}{l}7 \mathrm{~m} \times 90 \mathrm{~mm} \\
\text { Round Bore }\end{array}$ & $\begin{array}{l}\text { Hybrid } \\
\text { Al. } \\
\times 800 \mathrm{~g}\end{array}$ & ${ }^{*} 2,000$ & $* 3,000$ \\
\hline
\end{tabular}

* predicted values, all others are actual

insulating plug at the breech of the gun. The glass microspheres were secured to the plug either electrostatically or with a spray adhesive. Typically, two capacitor modules charged to $7 \mathrm{kV}(54 \mathrm{~kJ})$ were discharged simultaneously into the gun. The fuse would vaporize into a plasma and be accelerated through the launcher, carrying the entrained microspheres to the target. The fact that both the plasma and the beads were accelerated required that particular attention be paid to differentiating the effects of the microspheres from those of the plasma. While the impact craters on the targets made by the beads were clearly different from any plasma effects, the velocities were assumed to be the same. Several methods to strip the plasma from the beads prior to target impact met with limited success. Additional tests have been proposed.

\section{Small Caliber Rep-Rated Launcher}

Under a contract supported by the Joint Services Small Arms Program a rep-rateable, skid mounted, 0.60 caliber $1.6 \mathrm{~m}$ long EM launcher and power supply is in fabrication at CEM-UT [4]. The skid (fig. 1) will weigh less than $1,100 \mathrm{~kg}$ and includes the launcher and autoloader, the compulsator power supply, a silicon controlled rectifier (SCR) switch and the torque management system to compensate for the torque developed when the compulsator discharges. The only additional components required for firing the system in the field are the hydraulic motors, bearing sumps, and nitrogen and vacuum supplies.

The 0.60 launcher incorporates primary rails of molybdenum to reduce the bore damage normally associated with solid or plasma armature launchers. Copper secondary rails running parallel to the primaries and car- 


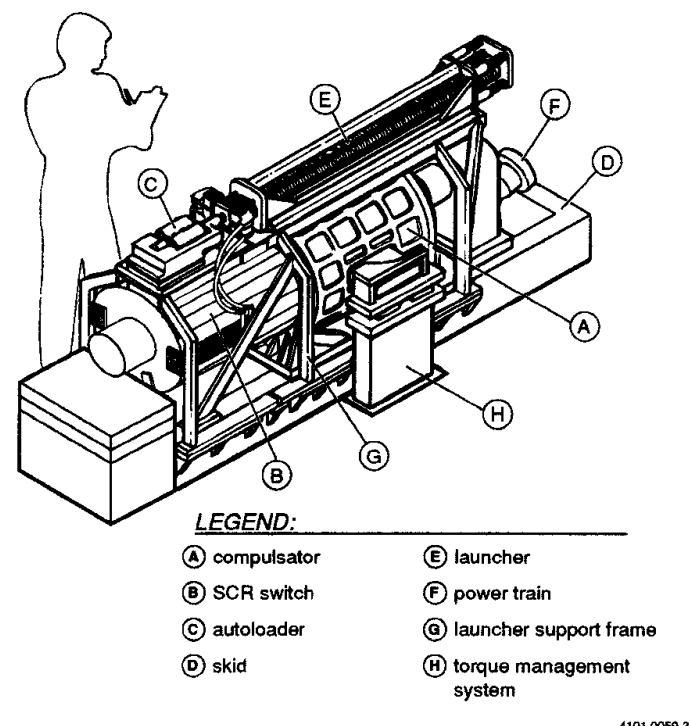

Figure 1. Small caliber launcher and power supply

rying current in the same direction are used to augment the primary rails. The augmentation increases the $L^{\prime}$ of the launcher to $1.25 \mu \mathrm{H} / \mathrm{m}$ vs. $0.37 \mathrm{H} / \mathrm{m}$ for the same geometry without augmentation. Rail insulators are fabricated by potting polyurethane in place around the rails after they are inserted into the gun support structure.

This gun is designed to fire a three shot salvo of solid aluminum armatures and projectile packages with masses of $32 \mathrm{~g}$ at velocities up to $2,000 \mathrm{~m} / \mathrm{s}$. The objective of the U-shaped solid armature design is to provide an adequate contact surface with good mechanical compliance while maintaining sufficient current-carrying capability. This is accomplished by machining a half degree taper into the $12.7 \mathrm{~mm}$ long contact surface, which results in a 0.23 $\mathrm{mm}$ interference fit on the diameter at the rear of the contact and a line-to-line fit at the front. This assures that the contacts are adequately loaded against the rails for the initial surge of current which starts the armature moving from its static position. Because the armature is designed with compliance in mind, as it moves down the bore and the contacts are worn away, the magnetic pressure continues to force additional contact material against the rails. Even with a compliant design most solid armature designs transition to a plasma armature at approximately $1,000 \mathrm{~m} / \mathrm{s}$ [5]. Because of this transitioning solid armatures are sometimes referred to as hybrid armatures.

While other programs have produced higher muzzle energies this compact power supply will operate at higher energy and power densities than any system previously tested at CEM-UT. This is accomplished primarily by using a compensated pulsed alternator (compulsator), invented by CEM-UT engineers in 1978 [6] as the prime railgun power and power conditioner. Energy density in the compulsator running at $25,200 \mathrm{rpm}$ will be $12 \mathrm{~kJ} / \mathrm{kg}$ vs. $2.7 \mathrm{~kJ} / \mathrm{kg}$ for capacitors, and $4 \mathrm{~kJ} / \mathrm{kg}$ for homopolar generators (HPGs) [7]

\section{MJ Single Shot Laboratory Gun}

As part of a program to develop alternative tactical weapons, DARPA and ARDEC have funded the design, fabrication, and testing at CEM-UT of one of the highest muzzle energy railgun systems tested to date. It consists of a $10 \mathrm{~m}$ long, $90 \mathrm{~mm}$ round-bore launcher powered by six HPG charged inductive stores[8]. During the railgun test program, a number of hybrid armatures and projectile packages are being tested in the $50 \mathrm{~m}$ deep vertical test range depicted in figure 2. Prior to testing, computer simulations are run to determine the preferred current profile and predict system performance. During projectile flight, high speed films, X-rays, muzzle voltage, and velocity/acceleration profiles are recorded along with power supply operating parameters. Diagnostics in the vertical range include four Scandiflash model $300 \mathrm{kV}$ flash $\mathrm{x}$-ray units and four high speed $16 \mathrm{~mm}$ Photonic, Photec IV, rotating prism cameras capable of 20,000 frame/s operation with rippleflash units for back or front lighting. Three additional x-ray units at the target and a coppervapor laser operating at $20,000 \mathrm{~Hz}$ (to provide increased lighting for filming projectiles) are also being installed. Inbore diagnostics include gun current, breech and muzzle voltage and B-dot probes.

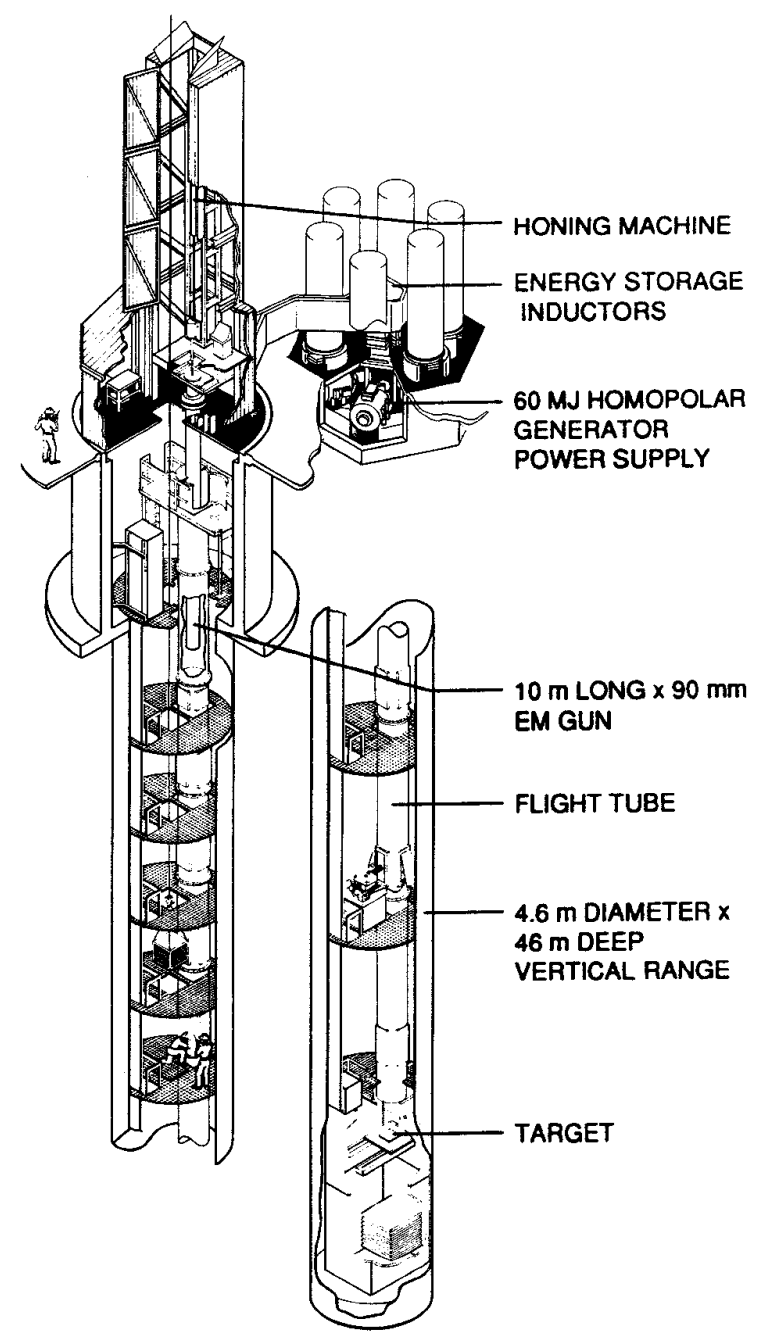

Figure 2. Vertical test range at CEM-UT 
The $10 \mathrm{~m}$ long gun (fig. 3) uses a replaceable rail assembly constructed of four $90^{\circ}$ sectors. The L' of the 90 $\mathrm{mm}$ gun has been measured at $0.37 \mu \mathrm{H} / \mathrm{m}$. The gun design and rail replacement technique was initially confirmed through testing of a half-scale, 45-mm bore gun, $3-\mathrm{m}$ long which is operational but mothballed at the present time. After machining the rail/insulator package to an $18 \mathrm{~cm}$ outer diameter (OD) it was inserted into a rail support structure, composed of ceramic disks and a forged steel pressure vessel. The rails were then preloaded by pressurizing an annulus of hydraulic fluid to $225 \mathrm{MPa}(32.5 \mathrm{kpsi})$. This prestressing is required to contain the bore pressure, $373 \mathrm{MPa}$ (54.1 kpsi), caused by the peak gun current of 3.2 MA

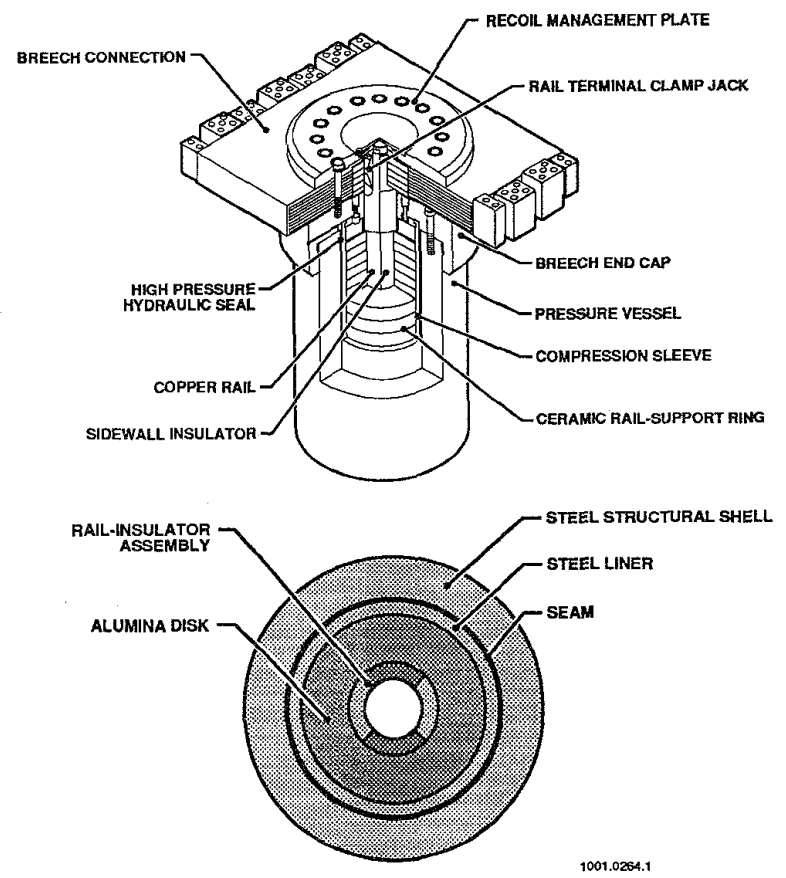

Figure 3. Single shot gun structure

To date the highest performance shot on the $9 \mathrm{MJ}$ gun system has been an 8.1 MJ shot of a 2,440 g hybrid aluminum armature with integral payload at a muzzle velocity of $2,557 \mathrm{~m} / \mathrm{s}$. A total of 37 shots have been fired with this launcher, with approximately half of those exceeding $4.0 \mathrm{MJ}$ of muzzle energy.

\section{MJ Lightweight Range Gun System}

While the $9 \mathrm{MJ}$ single shot gun system has been a useful tool in testing full scale armature and projectile packages even more remains to be learned from the field based system now under construction. The system (fig. 4) which includes a self contained power supply and rep-rateable gun with elevation capability is funded by the U. S. Army. The prime power for the system is provided by a General Electric LM500 gas turbine engine driving a 200 MJ compulsator through a speed increasing gear box and slip clutch arrangement. Rotating at $8,250 \mathrm{rpm}$ the compulsator has a peak design current of $3.2 \mathrm{MA}$ and $20 \mathrm{GW}$ of peak power.

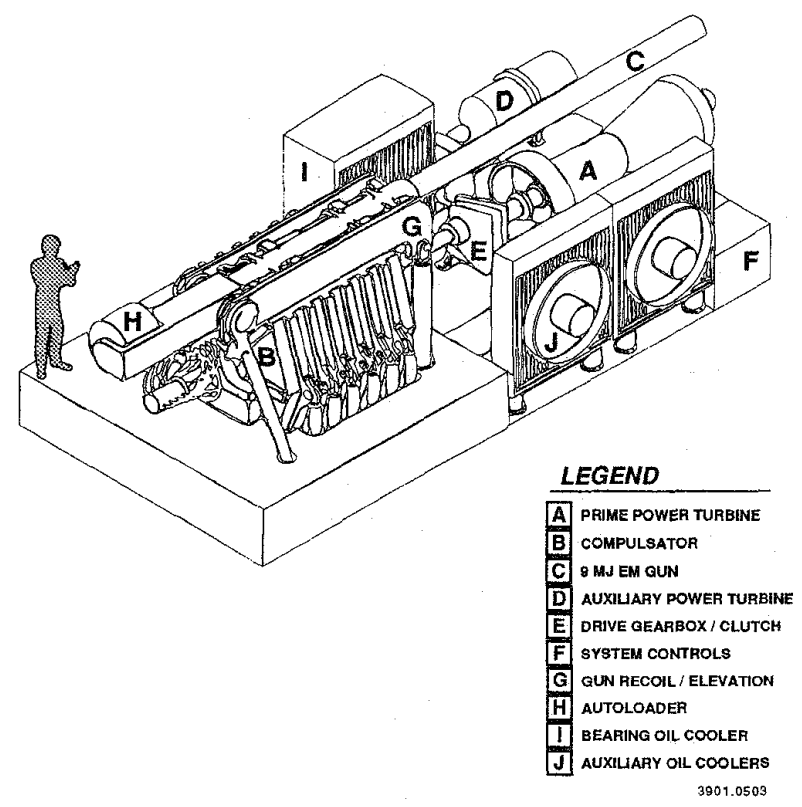

Figure 4. $9 \mathrm{MJ}$ range gun system

The range gun has a $90 \mathrm{~mm}$ round bore, is $7.5 \mathrm{~m}$ long and is designed to fire solid/hybrid armatures at up to $4 \mathrm{~km} / \mathrm{s}$. Even with the relatively short acceleration length, launch packages will see approximately the same acceleration as seen in the single shot gun and even less jerk. This is due to the slow rise time and flat pulse shape delivered by the compulsator. Because weight is an important consideration in this program the gun barrel and support structure weight has been limited to $3,700 \mathrm{~kg}$ compared to $30,000 \mathrm{~kg}$ for the laboratory based gun.

The rail and insulator package includes dispersion strengthened copper rails and pultruded glass insulators. Because the rails and insulators are both formed to their final shapes by an extrusion or pultrusion process the cost per set is less than one third the cost of a set of single shot gun rails and insulators. To isolate the rails and insulators from the steel support structure (fig. 5), the rail/insulator package received an overwrap of S-glass and epoxy. The support structure is composed of $1.3 \mathrm{~mm}$ thick 301 half hard stainless steel plates which are held together and insulated from each other with sheet adhesive. Individual insulated plates were used to prevent eddy currents from being created in the structure and reducing system efficiency. The L' for this configuration has been measured in the subscale gun at $0.47 \mu \mathrm{H} / \mathrm{m}$. While the stainless steel plates provide adequate radial stiffness they require additional support along the length of the gun. To provide that support the entire package receives a final overwrap of S-glass fiber and epoxy

Due to the rep-rateable requirement for this launcher several additional demands have been imposed upon it. Unlike the laboratory gun this gun will not be honed prior to each shot. While solid armatures are routinely launched in other guns without honing, armature performance may suffer after a number of shots. A honing system will be available to dress the bore as needed. 


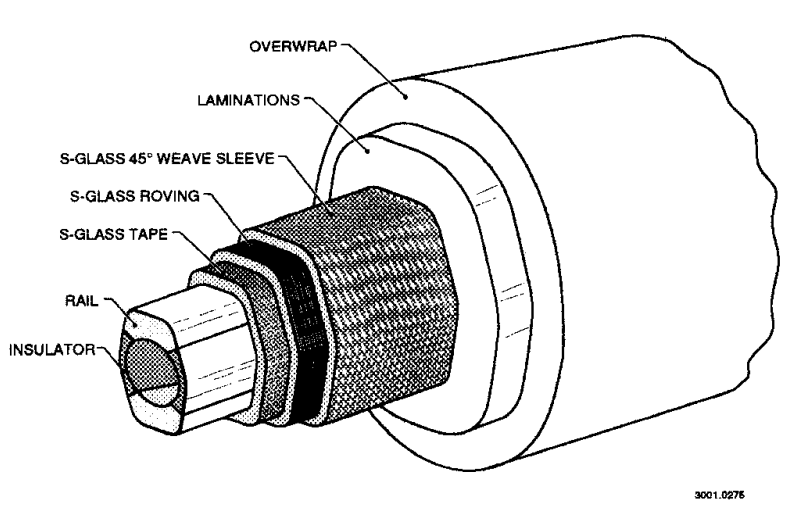

Figure 5. $9 \mathrm{MJ}$ range gun structure

Because the gun is designed to fire a nine shot salvo in three minutes at velocities up to $4 \mathrm{~km} / \mathrm{s}$ cooling the rails is critical. Cooling is accomplished by circulating an ethylene glycol solution through two cooling tubes brazed into the back of each rail. The $32^{\circ} \mathrm{C}$ solution circulates through the tubes at the rate of $60 \mathrm{l} / \mathrm{m}$. After a nine shot salvo the launcher temperature may reach $127^{\circ} \mathrm{C}$, still below the $140^{\circ} \mathrm{C}$ maximum temperature allowable for the pultruded insulators. The rep-rateable requirement also means that an autoloader must be fabricated to house and insert the projectile packages .

Testing of a one third scale version of this gun will begin in the next few months. Fabrication of the full scale gun and power supply is underway at present and acceptance testing is scheduled to begin in the fall of 1991.

\section{Conclusions}

Electromagnetic launchers can be used to accelerate a wide range of projectiles at velocities not readily achievable by conventional methods. Performance limits have not been reached and there is no limit on the variety of uses for these types of launchers. While a few of the existing programs at CEM-UT have been described, there are many other potential uses. These range from fusing metals to glass or other substrates to driving nails with a small, portable railgun/nailgun. Even the arc travelling down a launcher is being studied as a future replacement for conventional spark plugs in automobiles.

\section{Acknowledgments}

Martin Marietta Corporation and Lockheed provided the funding for the work on micrometeoroid impact simulations. The small caliber rep-rateable gun is funded by the Joint Services Small Arms Program. Both the $9 \mathrm{MJ}$ single-shot gun and lightweight range gun are funded by The U.S. Army through ARDEC and DARPA. CEM-UT gratefully acknowledges the support and encouragement received from these sponsors.

Without valuable contributions from the following individuals this paper would not have been possible: Jennifer Cox, Mike Ingram, Lori Moore, Sid Pratap, John Price, Jim Upshaw, and Mike Werst.

\section{References}

[1] R. C. Zowarka and W. F. Weldon, "Hypervelocity Electromagnetic Gun Development at CEM-UT," Air Ballistic Range Association Meeting, San Antonio, TX, October 1-4, 1985.

[2] D.A. Bresie, "Application of Pulse Power Technology to Induction Accelerators," presented at the 8th IEEE Pulsed Power Conference, San Diego, CA, June 17-19, 1991.

[3] J. L. Upshaw and J. P. Kajs, "Micrometeoroid Impact Simulations Using a Railgun Electromagnetic Launcher," IEEE Transactions on Magnetics, vol 27, no. 1, January 1991.

[4] R. L. Fuller, J. R. Kitzmiller, and M. W. Ingram, "Design and Testing of a 0.60 Caliber, Augmented Railgun," IEEE Transactions on Magnetics, vol 27, no. 1, January 1991.

[5] D. Kuhlmann-Wilsdorf, J. Cuadros, and M. E. Skidmore, "Hybrid Armatures: A New Type of High Speed High-Current Conduction Across Sliding Contacts," Proceedings 1987 International Current Collector Conference, Austin, Texas, November 1987 .

[6] U.S. Patent \#4,200,831

[7] J. H. Gully, M. L. Spann, J. A. Pappas, and S. B. Pratap, "Power Systems for Electrothermal Guns," Presented at 26th JANNAF Combustion Meeting, Jet Propulsion Laboratory, Pasadena, CA, October 1989.

[8] R. J. Hayes and R. C. Zowarka, "Experimental Results From CEM-UT's Single Shot 9 MJ Railgun," IEEE Transactions on Magnetics, vol 27, no. 1, January 1991.

[9] W.A. Walls, et al., "A Field Based, Self-Excited Compulsator Power Supply For A 9 MJ Railgun Demonstrator," IEEE Transactions on Magnetics, vol 27, no. 1, January 1991. 